\title{
Ergonomics Assessment and Work-Related Musculoskeletal Disorders in Construction Workers
}

\author{
Rabia Anwar ${ }^{1}$, Wajeeha Mahmood ${ }^{2}$, Hafiz Sheraz Arshad ${ }^{3}$ \\ ${ }^{1}$ Physical Therapist, Azra Naheed Medical College, Department of Physical Therapy, Main Raiwind Road,, Lahore \\ ${ }^{2}$ Lecturer, AzraNaheed Medical College, Department of Physical Therapy, Main Raiwind Road,, Lahore \\ ${ }^{3}$ Assistant Professor, Azra Naheed Medical College, Department of Physical Therapy, Main Raiwind Road, Lahore
}

\begin{abstract}
Background: Millions of worker are being affected by work related musculoskeletal disorders (WRMSDs) every year.(1) WRMSDs occur due to repetitive motions, heavy lifting and awkward working position like bending, twisting and kneeling. The purpose of this study is to determine significant association between posture risk level and prevelance of work related MSDs. Methods: It is a associational study was conduct in raiwand road and Multan road. We collect data through VAS, Nordic questioner and RULA assessment sheet. We collect data from 195-construction worker, participant's chi square test was used to check significant of the study,

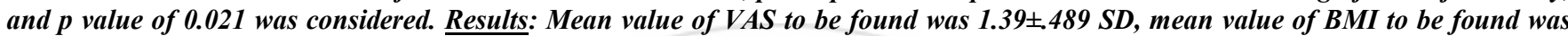

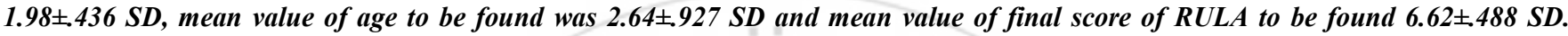
There was significant association between posture risk level and prevelance of low backache in construction workers as p value was 0.021. Low backache was found most prevalent in construction workers with frequency of 181(92.8\%). Conclusion: There was significant association between posture risk level and prevelance of low backache in construction workers. Low backache was found most prevalent in construction workers. Score of RULA indicated that further investigation and changes immediately were required ergonomically
\end{abstract}

Keywords: Work related musculoskeletal disorder (WMSDs), low back pain (LBP), ergonomic.

\section{Introduction}

\subsection{Overview}

Millions of worker are being affected by work related musculoskeletal disorders (WRMSDs) every year.(1) Our working population and health system are majorly affected by them which leads to their long-term sickness, absence from work and cause physical disabilities.(2)WRMSDs occur due to repetitive motions, heavy lifting and awkward working position like bending, twisting and kneeling. For example, bricklayers and drywall installers have musculoskeletal disorder due to their increase working in bent and twisting positions. Similarly, tile-workers spend more time in kneeled and stooped posture. Musculoskeletal disorders are $16 \%$ more in construction worker as compare to other. (Boschman et al., 2015)

"Ergonomics is the study of work action with significance on worker safety and productivity." The main outcome of ergonomics is to reduce musculoskeletal disorders(MSDs) and decrease work related injury.(3) The construction workers require ergonomics analysis to reduce MSDs caused by different awkward body posture and bad body positioning which can lead to MSDs. MSDs cause various injuries related to muscle, joints, nerves and blood vessels which also result in long term pain and time away from work.(4)

In construction industry, workers are engaged with highly physical demanding tasks which lead to musculoskeletal pain in different body regions.(5) Musculoskeletal disorder cause various injuries related to muscle, joints, nerves and blood vessels which also result in long term pain and time away from work.(6)
Musculoskeletal disorder highly affect lower back and waist in female than male. Where as hand, wrist, elbow, shoulder and neck were also affected.(7) Musculoskeletal disorder also cause carpal tunnel syndrom and stress fracture due to repetetive stress like hammering, drilling, sawing and cutting sheet metal with seissors. Large evidence shows that rate of morbidity, mortality and trouma are more in construction industry worker as compare to other industry worker.(8). Less severe case of musculoskeletal disorders are ligamentum sprain or strain and tear.The injured body part do not work properly as before the accident.(9) Risk factors of musculoskeletal disorders are individual factor, biomechanical and psychosocial factors. Individual factors include body weight and age, biomechanical factors are awkward body posture and psychosocial factors are related to job need, type and size of weight lifting.(10)Different factors that cause imbalance of body are unstable surfaces, stairs,surface height, slippery ways, manipulated load on different surface levels.(9).

Musculoskeletal conditions are major problems in young workers related to construction at starting of their careers. So traning programs are held to avoid and reduce musculoskeletal conditions. Type and time of construction worker also play an important role to develop musculoskeletal disorders.(11)Manually lifting of heavy loads, if load hit the worker can lead to injury due to falling and slipping.Similarly, light weight lifting for prolonge period can cause fatigue. Envoirmental conditions can also cause musculoskeletal disorders like temperature, ventilation. In winter, construction work required more muscle force to handle tools, materials and also cause rapid fatigue.( Schneider, 2001). The psychosocial factors also play role in WRMSDs like mentaly burden, social help, 


\section{International Journal of Science and Research (IJSR)}

ISSN (Online): 2319-7064

Index Copernicus Value (2013): 6.14 | Impact Factor (2015): 6.391

family suport and job insecurity. (Ekpenyong and Inyang, 2014)

As for as previous studies, most studies were done in western countries. No proper study in pakistan has been conducted yet regarding musculoskeletal disorders in construction workers. I will conduct this research first time in pakistan on WRMSDs. I will conduct this research on male construction workers as males are more involved in this profession in our society. It is a common occopation in pakistan so that's way I will choise this topic and I have seen many patient with musculoskeletal pain in physisal therapy OPD.

\subsection{Objectives}

1: To determine frequency of work related MSDs in construction worker of lahore city. 2: To determine ergonomic assessment of construction workers of lahore city. 3: To determine association between posture risk level and frequency of work related MSDs.

\subsection{Rationale}

Musculoskeletal disorders are common among construction workers due to bad posture. This research will help to determine prevalence of WRMSDs and posture analysis at work station in construction workers. This will help to prevent further injury in construction workers and improve efficiency of work and quality of human life.

\subsection{Operational defination}

Nordic questionnaire and RULA assessment sheet and VAS will be used in this research. Nordic questionnaire defines the area of disorder in body, RULA assessment sheet defines the ergnomic positioning of body and VAS define intensity of pain. Validity of Nordic musculoskeletal questionnaire for mearing tool is $86 \%$.(12)

Reliability of VAS for measuring pain intensity is $90 \%$.(13)

\subsection{Hypothesis:}

Null hypothesis

There is no association between posture risk level and prevalence of low backache.

\section{Research hypothesis}

There was a significant association between posture risk level and prevalence of low backache

\subsection{Materials and Methods}

\subsubsection{Study design}

Associational study design was used in this research.

\subsubsection{Setting and Duration:}

This study was conducted at construction sites in multan road, raiwind road lahore within 3 months.

\subsubsection{Inclusion Criteria:}

- Construction workers within $20-50$ years of age will be included in this study.

- Workers with working experience of more than 1 year will be considered.

\subsubsection{Exclusion Criteria:}

- Construction workers with trauma at construction site and road traffic accident.

- Construction workers with recent infections, systemic disease and inflammotory conditions.

\subsubsection{Sampling technique:}

Simple random sampling technique was used.

\subsubsection{Data collection:}

Nordic questionnaire, RULA assessment sheet and VAS was used in this research. Goniometry was performed to do postural analysis for RULA assessment sheet.

\subsubsection{Sample size:}

Sample size is 195 constructure worker out of 20,000 worker population in lahore. This sample is calculated by Rao soft sample size calculater according to formulas

$\mathrm{x}=\mathrm{Z}\left({ }^{\mathrm{c}} / 100\right)^{2} \mathrm{r}(100-\mathrm{r})$

$$
\begin{aligned}
& \mathrm{n}=\mathrm{Nx} /((\mathrm{N}-1) \mathrm{E}+\mathrm{x}) \\
& \mathrm{E}=\operatorname{Sqrt}[\mathrm{N}-\mathrm{n}) \mathrm{x} / \mathrm{n}(\mathrm{N}-1)]
\end{aligned}
$$

The 5\% margin of error with $95 \%$ confidence level and $85 \%$ estimated response rate.

\subsubsection{Statistical tool:}

Chi square was used to find association between posture risk level and prevalence of low backache

\subsubsection{Ethical consideration:}

I will consider all the ethical values of participants, respect the respondents and never use the confidential information of subject for any purpose except for research purpose only.

\section{Results}

Age:

\begin{tabular}{|c|c|c|}
\hline Variables & Frequency & Percentage \\
\hline $15-25$ & 27 & 13.8 \\
\hline $26-35$ & 50 & 35.6 \\
\hline $36-45$ & 84 & 43.1 \\
\hline $46-55$ & 34 & 17.4 \\
\hline Total & 195 & 100 \\
\hline
\end{tabular}

Frequency of age between 15-25 were 27(13.8\%), frequency of age between $26-35$ were $50(35.6 \%)$, frequency of age 36 45 were $84(43.1 \%)$ and frequency of age between $46-55$ were $34(17.4)$.

BMI:

\begin{tabular}{|c|c|c|}
\hline Variables & Frequency & Percentage \\
\hline Underweight & 20 & 10.3 \\
\hline Normal & 158 & 81.0 \\
\hline Obese & 17 & 8.7 \\
\hline Total & 195 & 100 \\
\hline
\end{tabular}

Frequencies of construction worker having underweight worker were $20(10.3 \%)$, frequencies of worker having 


\section{International Journal of Science and Research (IJSR) \\ ISSN (Online): 2319-7064}

Index Copernicus Value (2013): 6.14 | Impact Factor (2015): 6.391

normal BMI were 158(81.0\%) and obese frequencies were $17(8.7 \%)$.

VAS:

\begin{tabular}{|c|c|c|}
\hline Variables & Frequency & Percentage \\
\hline Mild pain & 119 & 61.0 \\
\hline Moderate pain & 76 & 39.0 \\
\hline Severe pain & 0 & 0 \\
\hline Total & 195 & 100 \\
\hline
\end{tabular}

Frequencies of construction workers having mild pain were $119(61.0 \%)$, frequencies of moderate pain were $76(39.0 \%)$ and frequencies of severe pain were 0 .

Nordic:

\begin{tabular}{|l|l|l|}
\hline Variables & Frequency & Percentage \\
\hline Neck pain & & \\
yes & 149 & 76.4 \\
no & 46 & 23.6 \\
\hline Shoulder pain & & \\
right shoulder & 81 & 41.5 \\
left shoulder & 12 & 6.2 \\
both & 72 & 36.9 \\
no pain & 30 & 15.4 \\
\hline Elbow pain & & \\
right elbow & 52 & 26.7 \\
left elbow & 120 & 61.5 \\
both & 32 & 6.7 \\
no pain & 10 & 5.1 \\
\hline Wrist pain & & \\
right wrist & 68 & 34.9 \\
left wrist & 33 & 16.9 \\
both & 71 & 36.4 \\
no pain & 23 & 11.8 \\
\hline Upper back pain & & \\
Yes & 144 & 73.8 \\
No & 51 & 26.2 \\
\hline Lower back pain & 181 & 92.8 \\
yes & 14 & 7.2 \\
no & 21 & 10.8 \\
\hline Hip/thigh pain & 21 & 10.8 \\
right hip & 56 & 49.7 \\
left hip & 97 & \\
both & 30 & 15.4 \\
no pain & 96 & 10.3 \\
\hline Knee pain & 24.1 \\
right knee & 98.7 \\
left knee & & 50.3 \\
both & & \\
no pain & & \\
\hline Ankle/foot pain & & \\
right foot & left foot & \\
both & & \\
no pain & & \\
\hline
\end{tabular}

Frequency of constructions worker having neck pain were $149(76.4 \%)$ and having no pain $46(23.6 \%)$. Frequency of constructions worker having right shoulder pain were $81(41.5 \%)$, frequency having left shoulder pain were $12(6.2 \%)$, frequency having both shoulders pain were $72(36.9 \%)$ and frequency having no pain were $30(15.4 \%)$. Frequency of construction worker having right elbow pain were $52(26.7 \%)$, frequency having left elbow pain were $120(61.5 \%)$, frequency having both elbows were $32(6.7 \%)$ and frequency having no pain were $10(5.1 \%)$. Frequency of construction worker having right wrist pain were 68(34.9\%), frequency having left elbow pain were 33(16.9\%), frequency of both wrist pain were71 (36.4\%) and frequency having no pain23 $(11.8 \%)$. Frequencies of construction worker having upper back pain were $144(73.8 \%)$ and having no pain were $51(26.2 \%)$. Frequencies of lower back pain were $181(92.8 \%)$. Frequency of right and left hip were $21(10.8 \%)$, frequency of both hip were $56(28.7 \%)$.

Frequencies of construction worker having right knee pain were $30(15.4 \%)$, frequencies of left knee pain were $20(10.3 \%)$ and frequency of both knee were $47(24.1 \%)$. Frequencies of construction worker having right ankle/foot pain were $22(11.3 \%)$, frequencies of left ankle/foot pain were $19(9.7 \%)$ and frequency of both foot were $58(29.7 \%)$.

RULA Assessment:

\begin{tabular}{|c|c|c|}
\hline Variables & Interpretation & Frequency \\
\hline $1-2$ & Acceptable & 0 \\
\hline $3-4$ & Investigate further & 0 \\
\hline $5-6$ & Investigate further and change soon & 75 \\
\hline 7 & Investigate further and change immediately & 120 \\
\hline
\end{tabular}

Frequencies of upper arm position were 133(68.2\%), frequency of lower arm position were 177(90.8\%) and frequency of trunk position were $118(60.5 \%)$. Mean value of VAS to be found was $1.39 \pm .489 \mathrm{SD}$, mean value of BMI to be found was $1.98 \pm .436 \mathrm{SD}$, mean value of age to be found was 2.64 $\pm .927 \mathrm{SD}$ and mean value of final score of RULA to be found $6.62 \pm .488 \mathrm{SD}$. There was significant association between posture risk level and prevelance of low backache in construction workers as $p$ value was 0.021 . Low backache was found most prevalent in construction workers with frequency of $181(92.8 \%)$.

\begin{tabular}{|l|c|c|c|} 
Chi square test: \\
\begin{tabular}{|c|c|c|c|}
\hline & Value & df & significant \\
\hline Person chi-square & 5.342 & 1 & .25 \\
\hline
\end{tabular}
\end{tabular}

\section{Discussions}

In this research, we found that the construction worker having 36.9\% shoulder pain and other researches shows $11 \%(14)$. The frequency of right shoulder pain is higher then left shoulder pain because construction workers mostly do their work with right hand. We found higher frequency of neck pain $76.4 \%$ but other research shows $25.3 \%$, (6). We found that highest problem of constructions workers, which affect the quality of work and life is LBP $92.8 \%$ but other research found $30.9 \%(10)$. The higher frequency of LBP is due to different awkward body posture and bad body positioning. We determine that the workers having knee pain $24.1 \%$ and other research show $38.4 \%$. We show less knee problems as compare to other research and having wrist problems $36.4 \%$ but other research show $42.4 \%$.(11)

\section{Conclusion}

There was significant association between posture risk level and prevelance of low backache in construction workers. Low backache was found most prevalent in construction workers. Score of RULA indicated that further investigation and changes immediately were required ergonomically 


\section{International Journal of Science and Research (IJSR) \\ ISSN (Online): 2319-7064}

Index Copernicus Value (2013): 6.14 | Impact Factor (2015): 6.391

\section{Limitations/Recommendations}

Further investigations required for ergonomic assessment

\section{References}

[1] Boschman JS, Frings-Dresen MH, van der Molen HF. Use of Ergonomic Measures Related to Musculoskeletal Complaints among Construction Workers: A 2-year Follow-up Study. Safety and Health at Work. 2015.

[2] Gouttebarge V, Wind H, Kuijer PP, Sluiter JK, FringsDresen MH. Construct validity of functional capacity evaluation lifting tests in construction workers on sick leave as a result of musculoskeletal disorders. Archives of physical medicine and rehabilitation. 2009;90(2):302-8

[3] Jacobs K. Ergonomics for therapists: Elsevier Health Sciences; 2008.

[4] Rahman CM. Study and analysis of work postures of workers working in a ceramic industry through rapid upper limb assessment (RULA). International Journal of Engineering. 2014;5(03):8269.

[5] Caban-Martinez AJ, Lowe KA, Herrick R, Kenwood C, Gagne JJ, Becker JF, et al. Construction workers working in musculoskeletal pain and engaging in leisure-time physical activity: Findings from a mixed-methods pilot study. American journal of industrial medicine. 2014;57(7):819-25.

[6] Ekpenyong CE, Inyang UC. Associations Between Worker Characteristics, Workplace Factors, and WorkRelated Musculoskeletal Disorders: A Cross-Sectional Study of Male Construction Workers in Nigeria. International Journal of Occupational Safety and Ergonomics. 2014;20(3):447-62.

[7] Guo H-R, Chang Y-C, Yeh W-Y, Chen C-W, Guo YL. Prevalence of musculoskeletal disorder among workers in Taiwan: a nationwide study. Journal of occupational health. 2004;46(1):26-36.

[8] Rosecrance JC, Porszasz J, Cook TM, Fekecs E, Karácsony T, Merlino L, et al. Musculoskeletal disorders among construction apprentices in Hungary. Central European journal of public/health. 2001;9(4):183.

[9] Schneider SP. Musculoskeletal injuries in construction: a review of the literature. Applied occupational and environmental hygiene. 2001;16(11):1056-64.

[10] Latza U, Karmaus W, Stürmer T, Steiner M, Neth A, Rehder U. Cohort study of occupational risk factors of low back pain in construction workers. Occupational and environmental medicine. 2000;57(1):28-34.

[11] Merlino LA, Rosecrance JC, Anton D, Cook TM. Symptoms of musculoskeletal disorders among apprentice construction workers. Applied occupational and environmental hygiene. 2003;18(1):57-64.

[12] Pinheiro FA, Tróccoli BT, Carvalho CVd. Validity of the Nordic Musculoskeletal Questionnaire as morbidity measurement tool. Revista de Saúde Pública. 2002;36(3):307-12.

[13] Bijur PE, Silver W, Gallagher EJ. Reliability of the visual analog scale for measurement of acute pain. Academic emergency medicine. 2001;8(12):1153-7.
[14] Boschman JS, Frings-Dresen MH, van der Molen HF. Use of Ergonomic Measures Related to Musculoskeletal Complaints among Construction Workers: A 2-year Follow-up Study. Safety and Health at Work. 2015;6(2):90-6.

\section{Author Profile}

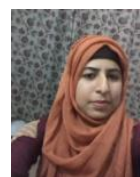

Rabia Anwar is AzraNaheed Medical College, Department of Physical Therapy, Main Raiwind Road,, Lahore

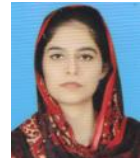

Wajeeha Mahmood is Lecturer, AzraNaheed Medical College, Department of Physical Therapy, Main Raiwind Road, Lahore

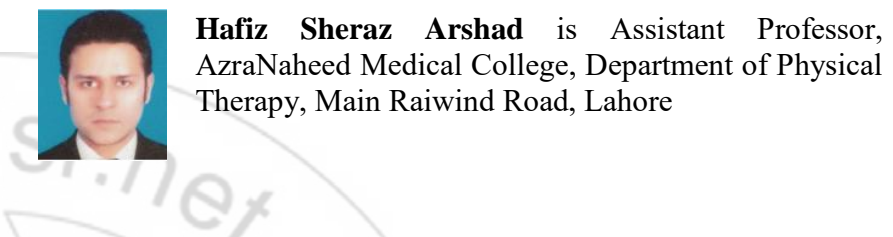

